\title{
СПЕКТРАЛЬНОЕ ИССЛЕДОВАНИЕ КОМПЛЕКСООБРАЗОВАНИЯ МОЛЕКУЛ ФОТОХРОМНОГО ФУНКЦИОНАЛИЗИРОВАННОГО ХРОМЕНА В РАСТВОРАХ
}

\begin{abstract}
Т.М. Валова ${ }^{1}$, А.М. Горелик ${ }^{1}$, В.А. Барачевский ${ }^{1,2}$
${ }^{1}$ Центр фотохимии Федерального научно-исследовательского центра «Кристаллография и фотоника» РАН, ул. Новаторов, д. 7а, к.1, Москва, Российская Федерация, 119421 E-mail: tatv.photonics@mail.ru,77gorelik@mail.ru, barachevsky@mail.ru ${ }^{2}$ Межведомственный центр аналитических исследований в области физики, химии и биологии при Президиуме РАН, ул. Профсоюзная ул., д. 65, стр.6, Москва, Российская Федерация, 117997

Проведено спектральное исследование комплексообразования молекул фотохромного функционализированного хромена в ацетонитриле и в водно-ацетонитрильной смеси. Обнаружено, ито металлокомплексы хромена в ацетонитрильном растворе проявляют положительный фотохромизм. В водно-ацетонитрильном растворителе вместо фотоиндуцированных металлокомплексов наблюдаются фотоиндуцированное образование протонированных комплексов отрытой формы исследованного фотохромного соединения.
\end{abstract}

Ключевые слова: фотохромизм, хромен, спектроскопия, ионы металлов, комплексообразование, протонированные комплексы

\section{SPECTRAL STUDY OF COMPLEX FORMATION OF PHOTOCHROMIC FUNCTIONALIZED CHROMENE MOLECULES IN SOLUTIONS}

\begin{abstract}
T.M. Valova ${ }^{1}$, A.M. Gorelik ${ }^{1}$, V.A. Barachevsky ${ }^{1,2}$
${ }^{1}$ Photochemistry Centre of the Federal Scientific Research Centre "Crystallography and Photonics" of the Russian Academy of Sciences. Street Novatorov, 7a, bld. 1, Moscow, Russian Federation, 119421

E-mail: tatv.photonics@mail.ru,77gorelik@mail.ru, barachevsky@mail.ru

${ }^{2}$ Interdepartmental Center of Analytical Research in the field of physics, chemistry and biology at the Presidium of the the Russian Academy of Sciences. Street Profsoyuznaya 65, bld. 6, Moscow, Russian Federation, 117997

A spectral study of the complexation of photochromic functionalized chromene molecules in acetonitrile and in a water-acetonitrile mixture has been carried out. It was found that chromene metal complexes in acetonitrile solution exhibit positive photochromism. In an aqueous -acetonitrile solvent, instead of photoinduced metal complexes, photoinduced formation of protonated complexes of the open form of the studied photochromic compound is observed.
\end{abstract}

Key words: photochromism, chromenes, spectroscopy, metal and protonated complexes

Для цитирования:

Валова Т.М., Горелик А.М., Барачевский В.А. Спектральное исследование комплексообразования молекул фотохромного функционализированного хромена в растворах. Рос. хим. ж. (Ж. Рос. хим. об-ва). 2021. T. LXV. № 4. C. 82-87

For citation:

Valova T.M., Gorelik A.M., Barachevsky V.A. Spectral study of complex formation of photochromic functionalized chromene molecules in solutions. Ros. Khim. Zh. 2021. V. 65. N 4. P. 82-87 


\section{ВВЕДЕНИЕ}

Среди различных возможных применений фотохромных систем [1] особый интерес вызывают фотохромные соединения, которые могут быть использованы для создания оптических сенсоров катионов металлов на основе явления комплексообразования между молекулами фотохромных соединений и ионами металлов $[2,3]$. Эти комплексы могут проявлять как положительный (обратимый переход из бесцветной А в окрашенную В форму под действием УФ света), так и отрицательный фотохромизм (обратимый переход из формы В в форму А под действием видимого света) схема 1. Наиболее интенсивные исследования в этом направлении проводились с использованием спиропиранов в органических растворителях [2, 3]. Среди фотохромных хроменов (нафтопиранов) наибольшее число работ посвящено изучению процессов комплексообразования краунированных производных, в которых ионы металлов встраиваются в краунированный фрагмент [2]. Исследованию процессов комплексообразования функционализированных хроменов иного типа практически не уделялось внимания. Только для 3Н-нафто[2,1-b] пирана с иминодиацетатными кислотными заместителями выявлена высокая эффективность комплексообразования молекул фотоиндуцированной окрашенной формы этого соединения с ионами $\mathrm{Ca}^{2+}, \mathrm{Mg}^{2+}$, and $\mathrm{Sr}^{2+}$, которая в десятки раз выше, чем с исходной циклической формой [4]. Для ряда незамещенных хроменов показана возможность получения протонных комплексов, проявляющих фотохромные превращения [5]. К сожалению, нет работ, посвященных использованию фотохромных хроменов для сенсорики ионов металлов в водных растворах, что представляет наибольший практический интерес.

Цель настоящей работы - сравнительное спектральное исследование процессов комплексообразования между молекулами фотохромного соединения из класса хроменов в ацетонитрильном и водно-ацетонитрильном растворах, а также в ацетонитриле в присутствии кислоты.

\section{ЭКСПЕРИМЕНТАЛЬНАЯ ЧАСТЬ}

В качестве объекта исследования использовалось фотохромное соединение из класса нафтопиранов - 3-(4-метоксифенил)-3-(2-тиенил)-5-морфолинокарбонил-3Н-нафто[2,1-b]пиран (ХР) [6], который был синтезирован по известной методике $[7,8]$.<smiles>[R10]OCCN1CCOCC1</smiles>

Для изучения процессов комплексообразования использовались безводные соли магния $\mathrm{Mg}\left(\mathrm{ClO}_{4}\right)_{2}$ (кат. № 222283, Aldrich) и тербия $\mathrm{Tb}\left(\mathrm{NO}_{3}\right)_{3}$ (кат. № 217212, Aldrich).

Сравнительные исследования выполняли в ацетонитриле (кат. № 271004, Aldrich) и в смеси растворителей, содержащих воду (бидистиллат) и ацетонитрил в объемном соотношени $4: 1$. Мольное соотношение концентраций СП и солей металлов составляло от $1: 10$ до 1:100. Во всех измерениях концентрация соединений в растворах $\mathrm{C}=4 \cdot 10^{-5} \mathrm{M}$ сохранялась неизменной.

Процессы протонирования хроменов изучались в ацетонитриле в присутствии хлорной кислоты $\mathrm{HClO}_{4}$ (кат. № 77227, Fluka).

Спектрально-кинетические измерения проводили с использованием спектрофотометра Cary 60 UV-Vis «Agilent Technologies» в кварцевой кювете с длиной оптического пути 1 см.

При проведении фотохимических исследований использовали осветитель LC-4 фирмы «Hamamatsu» с ксеноновой лампой L8253. УФ излучение выделяли стеклянным светофильтром УФС-1, а видимый свет - светофильтром ЖС-12.

\section{РЕЗУЛЬТАТЫ И ИХ ОБСУЖДЕНИЕ}

Фотохромизм хроменов подобен обратимым фотопревращениям спиропиранов (схема 1) [1].<smiles>[R2]C([R7])=CC=C1C=CC=CC1=O</smiles>

A

B

Схема 1 
В процессе фотохромных превращений исходного бесцветного фотохромного соединения (рис. 1, кр.1; табл. 1) в спектре поглощения возникает фотоиндуцированная полоса поглощения в видимом диапазоне с максимумом при 490 нм (рис. 1, кр. 2; табл.1).
В отличие от спиропиранов [2, 3] ведение перхлората магния в ацетонитрильный раствор хромена ХР не приводит к темновому образованию окрашенной формы В.

Таблица 1

Спектральные характеристики хромена XР и его комплексов с ионами металлов

\begin{tabular}{|c|c|c|c|c|c|}
\hline Растворитель & $\begin{array}{c}\text { Ион }\left(\mathrm{C}_{\mathrm{XP}}:\right. \\
\left.\mathrm{C}_{\text {ион }}\right)\end{array}$ & $\lambda_{\mathrm{B}}{ }^{\text {макс }}, \mathrm{HM}$ & $\Delta \mathrm{D}_{\mathrm{B}}{ }^{\text {фот }}$ & $\pm \Delta \lambda_{\mathrm{B}}, \mathrm{HM}$ & $\mathrm{k}_{\mathrm{TO}, \mathrm{c}^{-1}}$ \\
\hline \multirow{4}{*}{ Ацетонитрил } & - & 490 & 0,15 & - & 1,0729 \\
\cline { 2 - 6 } & $\mathrm{Mg}^{2+}(1: 100)$ & 560 & 0,26 & +70 & 0,4862 \\
\cline { 2 - 6 } & $\mathrm{Tb}^{3+}(1: 100)$ & $\begin{array}{c}435, \\
605\end{array}$ & $\begin{array}{l}0,33 \\
0,93\end{array}$ & +115 & 0,1055 \\
\hline \multirow{3}{*}{$\begin{array}{c}\text { Вода : ацето- } \\
\text { нитрил (4: } 1)\end{array}$} & $\mathrm{Mg}(1: 100)$ & 520 & 0,07 & +30 & 0,0222 \\
\cline { 2 - 6 } & $\mathrm{Tb}(1: 100)$ & 520 & 0,06 & +30 & 1,4742 \\
\hline
\end{tabular}

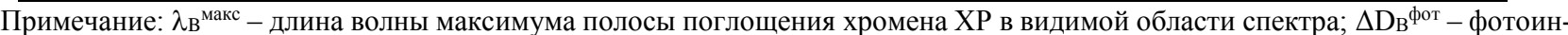
дуцированное изменение величины оптической плотности в максимуме полосы поглощения фотоиндуцированной формы; $\pm \Delta \lambda_{\mathrm{B}}$ - сдвиг максимума фотоиндуцированной полосы поглощения комплексов относительно максимума аналогичной полосы поглощения хромена XP; kто - константа темнового обесцвечивания.

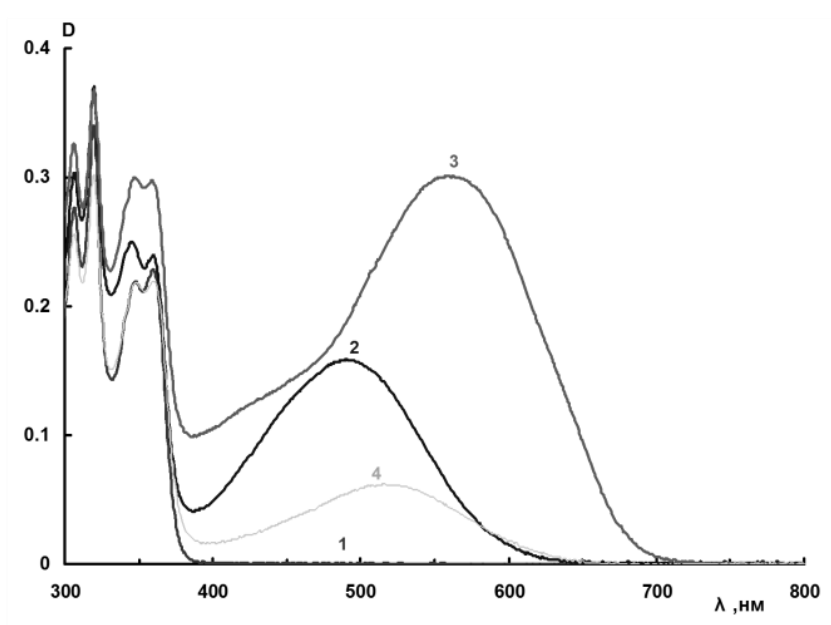

Рис. 1. Спектры поглощения соединения ХР до облучения в ацетонитриле (1), а также после УФ облучения без (2) и в присутствии перхлората магния в соотношении СХР : $\mathrm{C}_{\text {ион }}=1: 100$ в ацетонитриле (3) и в смеси вода : ацетонитрил (4:1) (4)

Введение в раствор ионов магния вызывает появление фотоиндуцированной длинноволновой полосы поглощения с максимумом при 560 нм (рис. 1, кр. 3), обусловленной образованием комплекса молекул ХР с ионами металлов. Эти комплексы в отличие от комплексов спиропиранов с ионами металлов проявляют положительный фотохромизм.
При использовании в качестве растворителя водно-ацетонитрильной смеси при УФ облучении раствора XР образуется окрашенный фотопродукт, харатеризующийся полосой поглощения с максимумом при 520 нм (рис. 1, кр. 4; рис. 2, кр. 2; табл. 1). Этот фотопродукт быстро исчезает при отключении активирующего излучения (рис. 2, кр. 3). Он проявляет положительный фотохромизм (рис. 3).

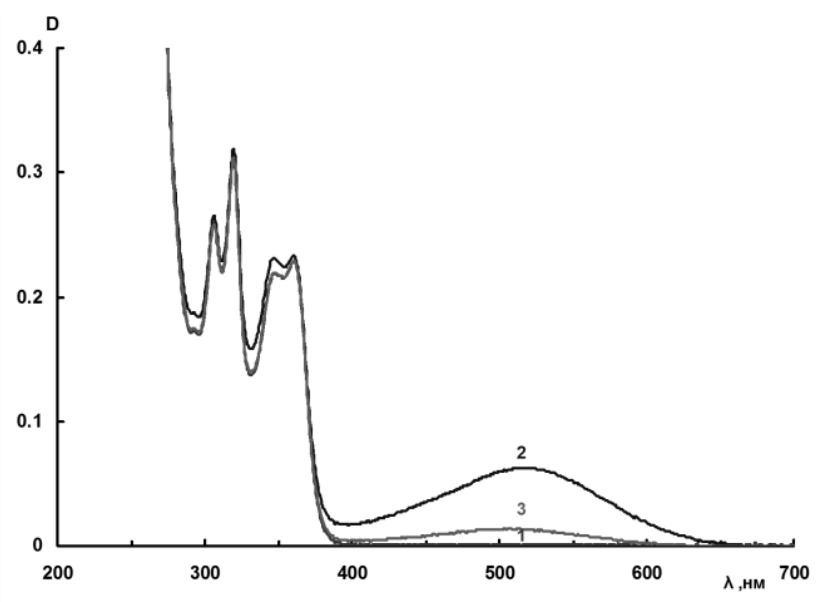

Рис. 2. Спектры поглощения соединения ХР до (1), после УФ облучения (2) и последующей темновой релаксации (3) в смеси вода: ацетонитрил $=4: 1 . \mathrm{CXP}_{\mathrm{X}}=4 \cdot 10^{-5} \mathrm{M}$ 
Подобные спектральные проявления обнаружены для соответствующих растворов без и в присутствии нитрата тербия (табл. 1). В отличие от комплексов XР с ионами магния комплексы с ионами тербия характеризуются полосой поглощения, максимум поглощения которой дополнительно сдвинут в длинноволновую спектральную область на 45 нм, что согласуется с данными электронного сродства этих ионов.

Увеличение содержания воды в ацетонитрильном растворе, содержащем комплексы ХР с ионами металлов приводит к постепенному преобразованию спектров поглощения (рис. 3).

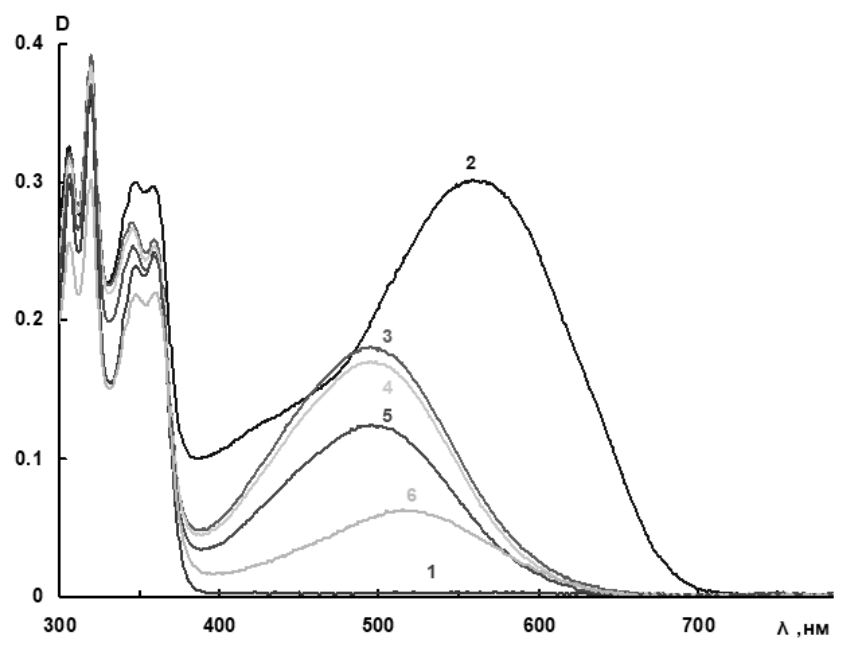

Рис. 3. Спектры поглощения соединения ХР в ацетонитриле в присутствии в растворе перхлората магния в соотношении $1: 100$ до (1), во время УФ облучения (2-6) и в процессе последовательного добавления воды

1 капля (3), 2 капли (кр. 4), 3 капли (5) и максимального количества воды в растворе в соотномении вода : ацетонитрил $=4: 1$ (6)

Анализ спектров поглощения, представленных на рис. 3, позволяет сделать вывод, что добавление воды вызывает разрушение фотохромных комплексов ХР с ионами металлов с одновременным образованием не светочувствительных протонированных комплексов.

В отличие от водно-ацетонитрильного раствора протонные комплексы ХР, возникающие в ацетонитриле в присутствии кислоты, проявляющие положительный фотохромизм, характеризуются двумя полосами поглощением фотоиндуцированной формы в видимой области спектра (рис. 4). Одна из них с максимумом при 490 нм, по-видимому принадлежит непротонированным молекулам фотоиндуцированной формы ХР, а вторая полоса с максимумом при 620 нм-протонному комплексу.

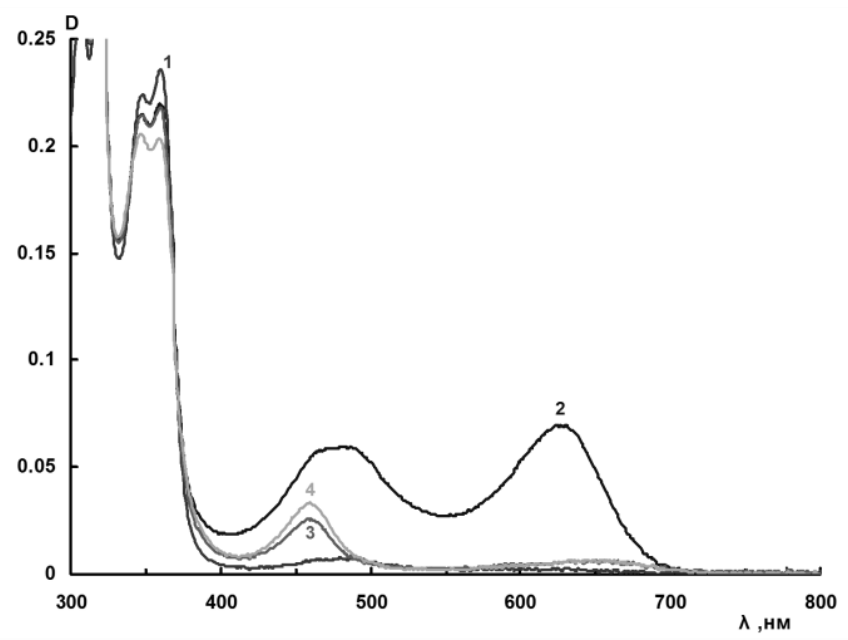

Рис. 4. Спектры поглощения соединения ХР в ацетонитриле в присутствии в растворе кислоты $\left(\mathrm{C}_{\mathrm{XP}}: \mathrm{C}_{\mathrm{HClO} 4}=1: 0,5\right)$ до (1), после УФ облучения (2) и последующей темновой релаксации $(3,4)$ $C_{X P}=4 \cdot 10^{-5} \mathrm{M} ; C_{\mathrm{HClO}^{4}}=4 \cdot 10^{-4} \mathrm{M}$

Обращает на себя внимание появление в процессе темнового обесцвечивания новой полосы поглощения с максимумом при 458 нм, интенсивность которой возрастает с временем темновой релаксации фотоиндуцированной окрашенной формы. Интенсивность этой полосы поглощения возрастает и с увеличением концентрации кислоты в ацетонитрилльном растворе при длительном хранении раствора в темноте (рис. 5). Соединение, возникающее после длительного хранения растворов ХР в присутствии кислоты, не проявляют фотохимических свойств.

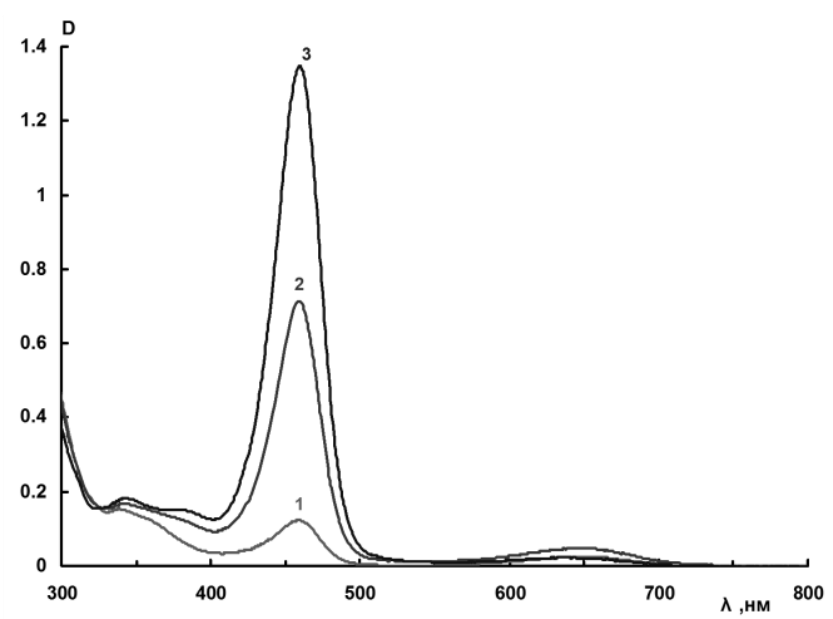

Рис. 5. Спектры поглощения соединения ХР в присутствии в растворе кислоты в мольном соотношении СХР: $\mathrm{C}_{\mathrm{HClO} 4}=1: 1$

(1), $1: 10$ (2) и $1: 100$ (3) через 18 часов после добавления кислоты в ацетонитриле $C_{X P}=4 \cdot 10^{-5} \mathrm{M} ; C_{H C l O 4}=4 \cdot 10^{-4} \mathrm{M}$ 
В отличие от хроменов, не содержащих морфалинового фрагмента [5], полученные результаты спектрального исследования кислотно-ацетонитрильных растворов можно объяснить образованием протонных комплексов двух типов (схема 2).

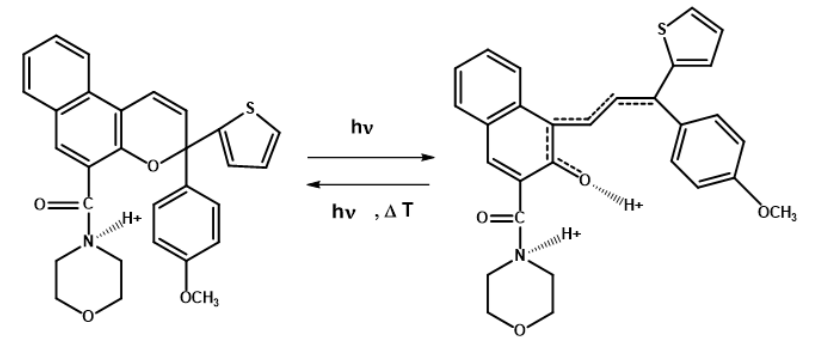

Схема 2

Не светочувствительный протонный комплекс образуется при взаимодействии протонов с морфалиновым фрагментом исходной циклической формой хромена. Его концентрация увеличивается с течением времени. Второй тип протонного комплекса, возникающий при взаимодействии протонов с фенолятным кислородом фотоиндуцированной открытой формы проявляет фотохромные свойства. Фотохромные комплексы образуются только с теми молекулами ХР, которые не образовали не светочувствительных комплексов первого типа. Третий тип протонных комплексов возникает в результате взаимодействия открытой формы ХР с молекулами воды. Все три типа протонных комплексов имеют селективные спектры поглощения.

Образование протонных комплексов, приводящее к разрушению металлокомплексов фотохромного хромена в водно-ацетонитрильных растворов и, следовательно, препятствующее сенсорике ионов металлов в водных растворах, требует разработки новых способов для определения ионов металлов в водных растворах. Одним из таких способов с использованием фотохромных соединений может быть применение промежуточного носителя ионов металлов [9]. Этот способ заключается в том, что на первом этапе ионы металла извлекаются из водного раствора с использованием пористой фильтровальной бумаги или другого носителя, обеспечивающего сорбцию ионов. После высушивания промежуточного носителя его помещают в ацетонитрильный раствор фотохромного хромена. Ионы, диффундирующие в раствор, образуют фотоиндуцированные окрашенные комплексы с молекулами фотохромного соединения, что обеспечивает спектрально-селективное определение их присутствие в водных растворах. Возможность реализации такого способа экспериментально доказана с использованием хромена ХР (рис. 6).

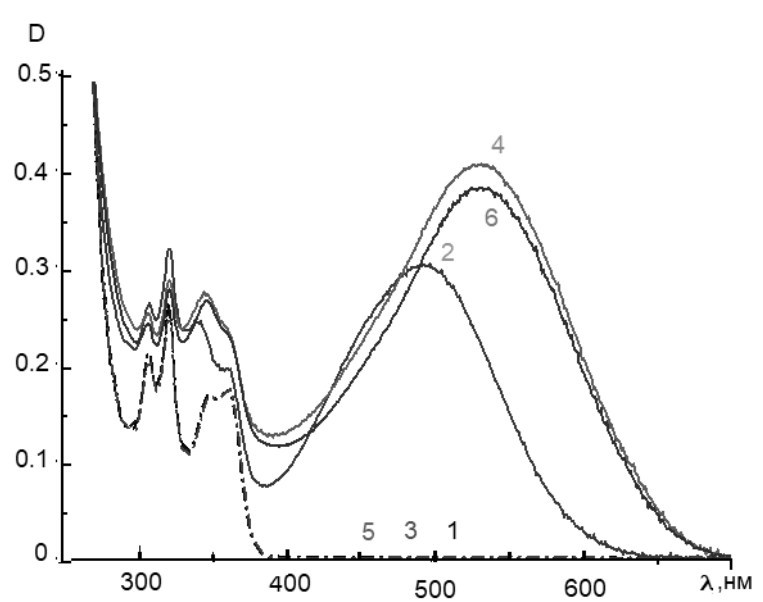

Рис. 6. Спектры поглощения ХР в ацетонитриле до (кр. $1,3,5)$ и после (кр. $2,4,6)$ облучения УФ-светом без $(1,2)$ и в присутствии ионов $\mathrm{Mg}^{2+}$, вымытых из фильтровальной бумаги $(3,4)$ и растворенных непосредственно в ацетонитриле $\left(\mathrm{C}=1 \cdot 10^{-2} \mathrm{M}\right)(5,6)$

Из рис. 6 следует, что спектры поглощения фотоиндуцированных комплексов молекул хромена XР в ацетонитриле, полученных с ионами магния, вымытыми из фильтровальной бумаги (рис. 6, кр. 4) и введенными непосредственно в раствор (рис. 6, кр. 6), практически совпадают, отличаясь от спектра фотоиндуцированной формы (рис.6, кр. 2) батохромным спектральным сдвигом.

\section{ВЫВОДЫ}

Молекулы ХР, содержащие морфалиновый фрагмент, при облучении УФ светом образуют в ацетонитриле окрашенные комплексы с ионами магния и тербия, которые обнаруживаются по появлению фотоиндуцированных полос поглощения в видимой области спектра с максимумами, батохромно сдвинутыми относительно полос поглощения фотоиндуцированной формы ХР в отсутствии ионов. Величина спектрального сдвига определяется электронными свойствами ионов. Образующиеся комплексы проявляют положительный фотохромизм.

В водно-ацетонитрильных растворах образование комплексов молекул ХР не наблюдается вследствие вытеснения ионов металлов с анионных центров молекул ХР протонами воды с образованием светочувствительных протонных комплексов, проявляющих положительный фотохромизм. Природа этих протонных комплексов отлична от природы тех, которые возникают при взаимодействии молекул ХР с молекулами хлорной 
кислоты. Исходная циклическая форма молекул ХP образует не светочувствительные протонные комплексы в результате взаимодействия с формалиновым фрагментом, концентрация которых возрастает со временем. В процессе образования этих комплексов возникают фотохромные протонные комплексы вследствие протонирования фенолятного кислорода открытой формы ХР.

С использованием результатов исследований предложен новый способ определения содержания ионов в водных растворах путем их абсорбции на промежуточном пористом носителе и последующей спектрофотометрии их комплексов с молекулами ХР в ацетонитриле.

Работа выполнена при поддержке Министерства науки и высшего образования в рамках выполнения работ по Государственным заданиям ФНИЦ «Кристаллография и фотоника» РАН: "(в части спектральных исследований), а также МЦАИ РАН (в части анализа результатов) ".

\section{ЛИТ Е Р А Т У Р А \\ REFERENCES}

1. Photochromic Materials: Preparation, Properties and Applications Eds. Tian H. and Zhang J. Wiley-VCH Verlag GmbH \& Co.Weinheim, Germany, 2016.

2. Paramonov S.V., Lokshin V., Fedorova O.A. Spiropyran, chromene or spirooxazine ligands: Insights into mutual relations between complexing and photochromic properties. J. Photochem. Photobiol. C. 2011. V. 12. P. 209-236. DOI: 10.1016/j.jphotochemrev.2011.09.001.
3. Барачевский В.A. Фотохромные спиросоединения и хромены для сенсорики ионов металлов. Обз. журн. химии. 2013. Т. 3. № 1. C. 58-103. DOI: 10.1134/S221811481204001X. Barachevsky V.A. Photochromic spirocompounds and chromenes for sensing metal ions. Rev. J. Chem. 2013. V. 3. P. 52-95. DOI: 10.1134/S221811481204001X.

4. Kumar S., Hernandez D., Hoa B., Lee Y., Yang J.S., McCurdy $A$. Synthesis, photochromic properties, and light-controlled metal complexation of a naphthopyran derivative. Organ. Lett. 2008. V. 10. No. 17. P. 3761-3764. DOI: 10.1021/ol801406b.

5. Gorelik A.M., Venidiktova O.V., Kobeleva O.I., Valova T.M., Barachevsky V.A. Spectral manifestation of protonation of photochromic naphthopyrans. Dyes and Pigments. 2021. V. 184. Art. 108833. DOI: 10.1016/j.dyepig.2020.108833.

6. Барачевский В.А., Кобелева О.И., Горелик А.М., Краюшкин М.M. Спектральные проявления взаимодействия наночастиц диоксида кремния с молекулами фотохромных соединений. Опт. и спектр. 2018. Т. 125. № 9. С. 348-352. DOI: 10.1134/S0030400X18090047. Barachevsky V.A., Kobeleva O.I., Gorelik A.M., Krayushkin M.M. Spectral manifestations of the interaction of silicon dioxide nanoparticles with molecules of photochromic compounds. Opt. Spectr. 2018. V. 125. N 3. P. 362-367. DOI: 10.1134/S0030400X18090047.

7. Pat. EP 1038870 (publ. 2000). Photochromic 3, 3-bis(aryl)-5((N-(un)substituted)amido)naphthopyrans, their preparation, compositions and polymer matrixes containing them and their use.

8. Пат. РФ 99106203 А (опубл. 2001). 3,3-Бис(арил)-5-[(N(не) замещенные амидо]нафтопираны, способ их получения, композиции и (со)полимерные матрицы, содержащие их. Pat. RU 99106203 A (publ. 2001). 3,3-Bis(aryl)-5[(N-(non) substituted amido]naphthopyrans, their preparation method, compositions and (co)polymer matrixes, containing them (in Russian).

9. Пат. РФ 2510013 C1 (опубл. 2014). Способ спектрофотометрического определения катионов металлов. Pat. RU 2510013 C1 (publ. 2014). Method for spectrophotometric determination of metal cations (in Russian).

Поступила в редакиию (Received) 01.08.2021

Принята к опубликованию (Accepted) 03.09.2021 